\title{
Landslide tsunami case studies using a Boussinesq model and a fully nonlinear tsunami generation model
}

\author{
P. Watts ${ }^{1}$, S. T. Grilli ${ }^{2}$, J. T. Kirby ${ }^{3}$, G. J. Fryer ${ }^{4}$, and D. R. Tappin ${ }^{5}$ \\ ${ }^{1}$ Applied Fluids Engineering, Inc., Private Mail Box 237, 5710 E. 7th Street, Long Beach, CA 90803, USA \\ ${ }^{2}$ Department of Ocean Engineering, Sheets Building, Narragansett Bay Campus, University of Rhode Island, Narragansett, RI \\ 02882, USA \\ ${ }^{3}$ Center for Applied Coastal Research, University of Delaware, Newark, DE 19716, USA \\ ${ }^{4}$ Hawaii Institute of Geophysics and Planetology, POST 602, University of Hawaii at Manoa, Honolulu, HI 96822, USA \\ ${ }^{5}$ Kingsley Dunham Centre, British Geological Survey, Keyworth, Nottingham, NG12 5GG, UK
}

Received: 8 October 2002 - Revised: 8 July 2003 - Accepted: 29 July 2003

\begin{abstract}
Case studies of landslide tsunamis require integration of marine geology data and interpretations into numerical simulations of tsunami attack. Many landslide tsunami generation and propagation models have been proposed in recent time, further motivated by the 1998 Papua New Guinea event. However, few of these models have proven capable of integrating the best available marine geology data and interpretations into successful case studies that reproduce all available tsunami observations and records. We show that nonlinear and dispersive tsunami propagation models may be necessary for many landslide tsunami case studies. GEOWAVE is a comprehensive tsunami simulation model formed in part by combining the Tsunami Open and Progressive Initial Conditions System (TOPICS) with the fully nonlinear Boussinesq water wave model FUNWAVE. TOPICS uses curve fits of numerical results from a fully nonlinear potential flow model to provide approximate landslide tsunami sources for tsunami propagation models, based on marine geology data and interpretations. In this work, we validate GEOWAVE with successful case studies of the 1946 Unimak, Alaska, the 1994 Skagway, Alaska, and the 1998 Papua New Guinea events. GEOWAVE simulates accurate runup and inundation at the same time, with no additional user interference or effort, using a slot technique. Wave breaking, if it occurs during shoaling or runup, is also accounted for with a dissipative breaking model acting on the wave front. The success of our case studies depends on the combination of accurate tsunami sources and an advanced tsunami propagation and inundation model.
\end{abstract}

\section{Introduction}

Submarine Mass Failures (SMF), or underwater landslides, are related terms that sometimes encompass submerged rock slides, reef failures, and many forms of sediment failure,

Correspondence to: P. Watts (phil.watts@ appliedfluids.com) inertial or not. SMF classification can be made on the basis of landslide morphology, material, or kinematics (Hampton et al., 1996; Turner and Schuster, 1996; Keating and McGuire, 2000). During an earthquake, water waves can be generated by both coseismic displacement and multiple SMFs during a single geological event. Likewise, we attribute all water waves, regardless of the possible sources, to a single tsunami event (Watts, 2001). The respective water wave features can be quite different for coseismic displacement and SMF tsunami sources. Coseismic displacement, or vertical seafloor deformation, often generates tsunamis with longer wavelengths and longer periods than those generated by SMFs, because of what is often a larger source area (Hammack, 1973; Watts, 1998, 2000). Specifically, the wavelength at the source is the horizontal extent of coseismic displacement on account of the presumably rapid bottom motion. Coseismic displacement generates tsunami amplitudes that correlate with earthquake magnitude (Hammack, 1973; Geist, 1998); SMFs produce tsunamis with amplitudes limited only by the vertical extent of center of mass motion or the water depth (Murty, 1979; Watts, 1998). SMF tsunamis therefore pose one of the greatest tsunami hazards to coastal population and infrastructure. Watts (2003), for instance, shows that roughly $30 \%$ of Pacific Basin tsunamis involve SMFs that have tsunami amplitudes higher than can be explained by an earthquake tsunami alone.

In this work, we demonstrate a hydrodynamic modeling strategy for SMF tsunamis (see Tappin et al., 1999, 2001; Watts et al., 2002) and we apply the strategy to historical case studies. Our modeling strategy is based on the traditional view of tsunamis involving three steps: generation, propagation, and inundation. In the case studies, little is usually known about the exact nature of the SMF that caused the tsunami. Hence, for simplicity, we only consider two idealized forms of SMFs as possible tsunami sources: underwater slides and underwater slumps. Underwater slides refer to thin, translational, failures that travel long distances, while underwater slumps refer to thick, rotational, failures, 


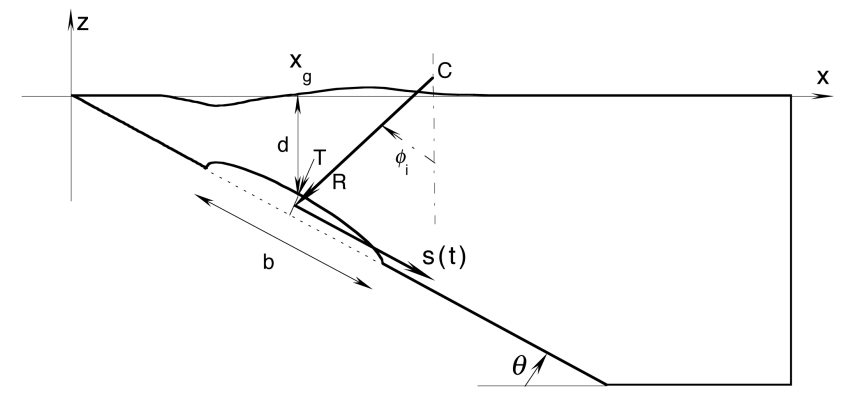

Fig. 1. Schematic diagram of model problems, for underwater slides and slumps, with 10 fold vertical exaggeration of the free surface amplitude.

which occur with minimal down-slope displacement (Prior and Coleman, 1979; Edgers and Karlsrud, 1982; Schwab et al., 1993). We are well aware that a whole spectrum of SMF mechanisms, combining slides and slumps, can occur in various situations, and specific features of a particular SMF can only be inferred from the detailed knowledge of local marine geology, sediment characteristics, and triggering mechanism. We will show, however, that our admittedly crude idealizations of SMF shape and motion, when combined with realistic field data from marine geology surveys and accurate hydrodynamic modeling, can simulate observed tsunami features and coastal runup of historical case studies with a considerable degree of accuracy, perhaps even improving on results from other models.

Our proposed modeling strategy combines three different models. (1) Wavemaker model: a model for the center of mass motion of SMFs (slides or slumps) and possible deformation rate around this center, as a function of material, geometrical, and hydrodynamic parameters. (2) Tsunami generation model: a model for tsunami generation due to the specified SMF shape and motion, based on results of both two- and three-dimensional (3-D) fully nonlinear potential flow models. (3) Tsunami propagation and inundation model: a model for tsunami propagation and inundation, based on extended fully nonlinear Boussinesq equations. The combined model, referred to as GEOWAVE, is applied to historical case studies, and results are compared to tsunami observations and records. A new name such as GEOWAVE is necessary to recognize that our modeling strategy involves creating an overarching superstructure that is more than just a combination of three existing models.

SMF tsunami events often require considerable marine geology data to produce realistic case studies. For example, underwater slide motion is characterized by at least a specific density $\gamma$, a landslide length along the incline $b$, a thickness $T$, a width $w$, and an incline angle $\theta$. Most of these SMF quantities can be estimated from bathymetry data acquired during a marine survey of suspected tsunami sources. In addition, underwater slumps require a radius of curvature $R$ and a shear strength $S_{u}$ to describe motion, because the highly restrained motion of a slump is dominated by basal friction, contrary to many slides with deposits situated far from the slide scar. Field measurements of these two quantities require more sophisticated seismic reflection and core sampling tools. In either case, it should be pointed out again that marine geology surveys conducted by experienced field geologists are essential for understanding, and eventually simulating, tsunamis generated by SMF (e.g. Tappin et al., 1999, 2001, 2002).

In the following, we briefly present features of our three model components and we then apply the combined model to three historical case studies.

\section{Wavemaker model}

A SMF is a wavemaker whose shape and motion must be prescribed. Following Grilli and Watts (1999), we idealize SMF geometry as a mound with elliptical cross-section translating along a straight incline with angle $\theta$ from horizontal (Fig. 1). The mound has a maximum thickness $T$ in the middle, a total length $b$ along the down-slope axis, a total width $w$ along the cross-slope axis, and an initial vertical submergence $d$ at the middle of the landslide. Following Grilli and Watts (2001) and Grilli et al. (2002), we further assume an elliptical planform, $b$ by $w$, for the SMF. The result is a realistic SMF shape that can be described by relatively few parameters. In particular, we can reproduce the long and thin nature of most SMF shapes, and thereby attribute the effect of realistic SMF length and thickness on tsunami generation. We clearly assume that the SMF moves as a single coherent event, although our analyses could equally well be applied to separate pieces of a retrogressive landslide.

A deforming body, such as a SMF, possesses a center of mass motion that defines the starting point in any motion analysis. Watts (1997) showed in laboratory experiments that the center of mass of a deforming material landslide moves in a manner almost identical to that of a solid block. Watts and Grilli (2003) further showed that SMF deformation is driven by SMF center of mass motion. Earlier computations (not detailed here) performed with our two-dimensional (2D) tsunami generation model (Fig. 2) showed that reasonably rapid SMF deformation about the center of mass appears to be a second order phenomenon in terms of tsunami generation. Hence, for the cases studied here, we assume that tsunami effects attributed to SMF deformation are negligible during the tsunami generation phase, i.e. $b(t)=b_{o}$ and so on. Using the wavemaker formalism of Watts (1998), we derive center of mass motions that are specific to mass failure type (i.e. slide or slump) and geometry. For many SMF tsunami case studies, these simple center of mass motions will provide a degree of sophistication that is commensurate with the available marine geology data and, as we will see, accurate enough to reproduce tsunami observations and records. For example, these center of mass motions reproduce the acceleration from rest that occurs for actual SMFs, and almost all tsunami generation occurs during this early acceleration motion. 


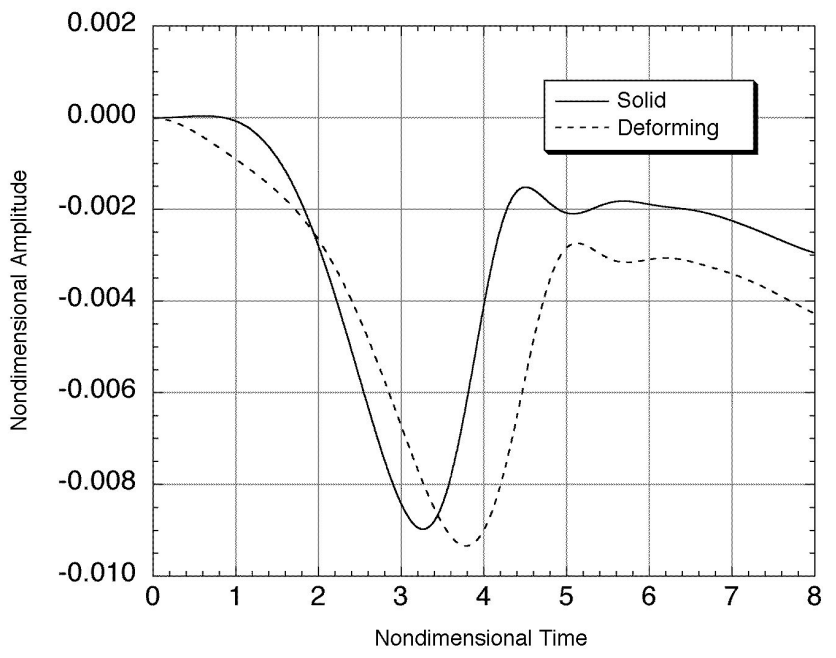

Fig. 2. Nondimensional characteristic tsunami amplitude $\eta^{\prime}=$ $\eta /\left(s_{O} \sin \theta\right)$ for: (- - ) solid; and (- - - - ) deforming slide, displayed as a function of nondimensional time $t^{\prime}=t \sqrt{g / b}$.

We model an underwater slide as a rigid body moving along a straight incline (Fig. 1) with center of mass motion $s(t)$ parallel to the incline and subject to external forces from added mass, gravity, and dissipation. If we assume a specific density $\gamma \cong 1.85$, a negligible Coulomb friction coefficient $C_{n} \cong 0$, an added mass coefficient $C_{m} \cong 1$, and a drag coefficient $C_{d} \cong 1$, then we can describe underwater slide motion with

$s(t)=s_{o} \ln \left[\cosh \left(\frac{t}{t_{o}}\right)\right]$

$a_{o} \cong 0.30 \mathrm{~g} \sin \theta$

$u_{t} \cong 1.16 \sqrt{b g \sin \theta}$

$s_{o} \equiv \frac{u_{t}^{2}}{a_{o}} \cong 4.48 b$

$t_{o} \equiv \frac{u_{t}}{a_{o}} \cong 3.87 \sqrt{\frac{b}{g \sin \theta}}$,

where $a_{o}$ is the initial acceleration, $u_{t}$ is the theoretical terminal velocity, $s_{o}$ denotes a characteristic distance of motion, and $t_{o}$ denotes a characteristic time of motion (see Watts, 1998, 2000; Grilli and Watts, 1999).

The dynamical coefficients are constrained by experimental work (e.g. Watts, 1997; Grilli and Watts, 2001; Grilli et al., 2002; Enet et al., 2003) and reasonable values do not have a strong impact on center of mass motion, nor by extension on tsunami generation. The values proposed here are well within the accepted range of well known and long ago published values. We note that the drag coefficient $C_{d}$ is based on landslide thickness (or cross-sectional area) rather than on landslide length (or surficial area). Watts and Grilli (2003) showed that many underwater slides can be expected to experience negligible Coulomb friction because gravitational forcing scales with SMF volume whereas basal friction scales with SMF area, drastically reducing the effect of Coulomb friction on the motion of tsunamigenic slides. Regardless, the effect of Coulomb friction can be folded into an effective incline angle $\theta$ without changing Eq. (1).

We model an underwater slump as a rigid body moving a small angle $\Delta \phi$ along a circular failure plane, subject to external moments from added mass, buoyancy, gravity, and shear stress summed over the failure plane. Multiplying this solution by the radius of curvature $R$ from the slump center of rotation $C$ to the center of mass (Fig. 1) gives the slump tangential motion along the failure arc. Using similar coefficient values as for slides, we find

$s(t)=s_{o}\left[1-\cos \left(\frac{t}{t_{o}}\right)\right]$

$a_{o} \cong 0.15 g \Delta \phi$

$u_{\max } \cong 0.27 \Delta \phi \sqrt{R g}$

$s_{o} \equiv \frac{u_{\max }^{2}}{a_{o}} \cong 0.50 R \Delta \phi$

$t_{o} \equiv \frac{u_{\max }}{a_{o}} \cong 1.84 \sqrt{\frac{R}{g}}$

where $\Delta \phi=\phi_{f}-\phi_{i}$ is the difference in slump angular position. We note that Eq. (2a) produces a maximum velocity during the middle of slump motion, for $t=\pi t_{o} / 2$, before returning to rest at the end of motion, $t=\pi t_{o}$. This occurs because the rotational slump works against gravity. Moreover, the basal shear strength $S_{u}$ along the failure plane that controls slump motion is implicitly contained in the angular difference $\Delta \phi$ swept by the slump.

Our SMF motion assumptions need only be valid for short times, defined here as $t<t_{o}$, which can be verified with Eqs. (1) and (2) to correspond to a center of mass displacement $s<0.5 s_{O}$ along the incline. Among other things, we feel free to assume a planar incline because the details of nearby bathymetry may not enter into tsunami generation at such short times. Likewise, our force balances are sufficiently detailed to produce a reasonable initial acceleration for the SMF center of mass, which is our primary objective. More details about the derivation of Eqs. (1) and (2) can be found in Watts (1998) and Watts et al. (2002), respectively.

\section{Tsunami generation model}

The first step in the traditional view of tsunamis is generation, for which we have several dedicated and accurate models. We calculate tsunami generation due to underwater slides moving according to Eq. (1) and due to underwater slumps moving according to Eq. (2) using the twodimensional model of Grilli and Watts (1999) or the threedimensional model of Grilli et al. (2002). These tsunami 
generation models are based on fully nonlinear potential flow equations solved with a Boundary Element Method (BEM), and have been independently validated both numerically and experimentally. SMF tsunami simulations can be performed with either tsunami generation model for a variety of SMF geometry and bottom slopes, i.e. the SMF parameters $b, d$, $T, w, \theta \ldots$. However, such simulations are computationally intensive, particularly in three dimensions, and, in those case studies that lack detailed marine geology data, may have to be repeated for a number of combinations of the SMF parameters. Another approach, followed here, is to compute once and for all tsunami features, such as wavelength and amplitude, as a function of a range of parameter values, and to express the features in the form of empirical relationships. These relationships can then be used for a rapid prediction of tsunami sources in lieu of running the BEM models. This is the basis of the predictive tool referred to as the Tsunami Open and Progressive Initial Conditions System (TOPICS).

To begin this process, we select the minimum surface depression above the middle of the initial slide or slump position as a characteristic SMF tsunami amplitude. We choose the minimum surface depression because it characterizes the depression wave situated above the SMF, which is perhaps the clearest and simplest measure of tsunami generation (Watts, 1997). Based on 2-D computations with the Grilli and Watts (1999) model, we find, for translational slides (and $\gamma \cong 1.85$ )

$\lambda_{o} \equiv t_{o} \sqrt{g d} \cong 3.87 \sqrt{\frac{b d}{\sin \theta}}$

$\eta_{2 d} \cong 0.2139 T\left(1-0.7458 \sin \theta+0.1704 \sin ^{2} \theta\right)\left(\frac{b \sin \theta}{d}\right)^{1.25}$

for characteristic wavelength and 2-D amplitude, respectively. Similarly, we find the equations predicting tsunami wavelength and 2-D amplitude for rotational slumps as

$\lambda_{o} \equiv t_{o} \sqrt{g d} \cong 1.84 \sqrt{R d}$

$\eta_{2 d} \cong 0.0654 T \Delta \theta^{1.39}(\sin \theta)^{0.22}\left(\frac{b}{d}\right)^{1.25}\left(\frac{R}{b}\right)^{0.37}$

also with $\gamma \cong 1.85$. In contrast with earthquake tsunamis, the wavelength depends on the duration of SMF motion, because there is usually ample time for water waves to propagate entirely out of the generation region while tsunami generation occurs (Watts, 1998).

We note that there have been other analytical estimates of SMF tsunami amplitude. One of two semi-empirical equations proposed by Striem and Miloh (1976) is reproduced by Murty (1979). The theoretical equation of Pelinovsky and Poplavsky (1996) was shown to produce reasonable tsunami amplitude predictions by Watts et al. (2000). These equations were all developed in two dimensions for landslides accelerating from rest. No tsunami wavelength estimate was provided. In contrast, the works of Grilli and Watts (1999) and
Goldfinger et al. (2000) provide predictive equations that are precursors to Eqs. (3) and (4) presented here. Ward (2001) as well as Tinti et al. (2001) develop tsunami generation equations for constant depth channels.

The ability to predict tsunami features such as wavelength and amplitude with Eqs. (3) or (4) enables one to construct SMF tsunami sources in a given situation, as a function of the SMF shape and motion parameters. This process essentially reconstructs the original BEM results from which Eqs. (3) and (4) were derived and so retains much of the original accuracy. To produce a tsunami source, we need to construct a realistic free surface elevation as an initial condition for the tsunami propagation model. The 3-D model of Grilli et al. (2002) enables us to relate the 2-D tsunami amplitudes predicted by Eqs. (3b) and (4b) to a 3-D tsunami amplitude $\eta_{o}$ found by the BEM model. Furthermore, the 3-D lateral spreading of waves as a function of landslide width $w$ enables the reconstruction of tsunami sources simply by using analytical functions of the horizontal coordinates. When the pieces of this puzzle are finally assembled, we find that we can construct 3-D landslide tsunami sources without any need for running either of the BEM models. When looking at Eqs. (3) and (4), we see that any explicit dependence of tsunami generation on SMF motion has apparently been lost. In reality, the SMF motion that produces the tsunami is implicit through use of the same SMF parameters as found in Eqs. (1) and (2) and as used for both 2-D and 3-D computations. Validation of this procedure can be achieved by running the 3-D model for the specific case under consideration and comparing the result with our analytical prediction.

The duration of landslide acceleration $t_{o}$ is also the duration of tsunami generation (Watts, 1998). During tsunami generation, almost all of the far-field wave energy is invested in potential energy above the SMF (Watts, 2000). The direct implication is that there is very little propagating wave energy invested in kinetic energy above the SMF. So, while the water column may be perturbed by SMF motion, the resulting water velocities remain insignificant for the purpose of tsunami generation. It is only during wave propagation in the far-field that an equi-partition of wave energy is approached, as about half of the potential energy is shunted into kinetic energy (Watts, 2000). These basic facts allow us to neglect water velocity at $t=t_{o}$ and focus solely on the free surface shape, as reconstructed from the characteristic wavelength and amplitude given by Eqs. (3) or (4). Thus, TOPICS provides an $a d$ hoc analytical free surface shape, from curve fits made at time $t=t_{o}$ as if the free surface results from the 3-D model of Grilli et al. (2002) were being transferred directly to a tsunami propagation model at that instant of time. The proper test of TOPICS is its ability to perform successful case studies, as we endeavor to demonstrate below.

TOPICS is currently able to produce tsunami sources for earthquakes, underwater slides, underwater slumps, debris flows, and pyroclastic flows. We consider the first three tsunami sources in this work. In order to compare SMF results to vertical coseismic displacement results, TOPICS defines earthquake tsunami sources from the half-plane solu- 
tion of an elastic dislocation problem (Okada, 1985). A planar fault of length $L$ and width $W$ is discretized into many small trapezoids and the point source solution of Okada (1985) is used to sum the contributions made by each trapezoid to vertical coseismic displacement, based on the actual depth of the trapezoid. The shear modulus $\mu$ can be specified based on the depth of the earthquake centroid as well as other seismic and geological descriptors. TOPICS outputs a characteristic wavelength $\lambda_{o}$ that is the larger of the fault dimensions $L$ or $W$, and a characteristic tsunami amplitude $\eta_{o}$ that is the minimum depression found from the coseismic displacement. The seismic moment $M_{o}$ is proportional to but slightly less than $\mu L W \Delta$ because a Gaussian slip distribution is assumed about the centroid, where there is a maximum slip $\Delta$. TOPICS currently allows for the superposition of up to nine fault planes, which can be assembled into complex fault structures or slip distributions. More information on TOPICS and the software licensing agreement can be found at www.tsunamicommunity.org.

\section{Tsunami propagation and inundation model}

The second and third steps in the traditional view of tsunamis are propagation and inundation, which can be accurately simulated with a single model. The greatest advantage in using a distinct tsunami propagation and inundation model is that it can be applied accurately over a much larger surface area than an accurate 3-D tsunami generation model. We simulate tsunami propagation and inundation using the long wave propagation model FUNWAVE (Chen et al., 2000; Kennedy et al., 2000) based on fully nonlinear Boussinesq equations, with an extended dispersion equation (Wei et al., 1995; Wei and Kirby, 1995), in the sense that it matches the linear dispersion relationship for deep water waves. FUNWAVE includes a breaker model and can simulate inundation of dry land. We had to make significant modifications of FUNWAVE in order to simulate an arbitrary tsunami initial condition over an arbitrary bathymetry.

The primary benefit of a Boussinesq wave propagation model over traditional nonlinear shallow water wave models is that horizontal velocities are no longer constrained to have a constant value over depth. During propagation and inundation, nonuniform horizontal velocity profiles over depth are most often encountered (i) when water waves propagate in deep water, (ii) when water waves runup onto a shoreline of intermediate slope, or (iii) when water waves become significantly nonlinear. A Boussinesq model enables accurate vertical tsunami runup and horizontal tsunami inundation in one simulation without the need for any user intervention. FUNWAVE uses the slot method to treat runup. In addition, while keeping all the nonlinear terms within the order of approximation, the dispersive properties of the fully nonlinear Boussinesq model allow for a more accurate representation of dispersive wave behavior occurring (a) during propagation from deep water, (b) during propagation of an undular bore (Mei, 1983), and (c) during propagation of edge waves
(Liu et al., 1998). Many of these wave phenomena can be seen on animations of our work that can be downloaded from www.tsunamicommunity.org.

The surface elevation of the SMF tsunami source predicted by TOPICS is introduced as an initial condition into FUNWAVE, at the characteristic time $t_{o}$ after the landslide starts moving inertially. The time at which the propagation model begins is thus fixed by SMF dynamics that are specific to each event. We demonstrate our simulation technique with three case studies that are by necessity quite brief. Our use of GEOWAVE simulations distinguishes this work from purely analytical estimates made for similar case studies. GEWOAVE has been designed to output numerical wave gauges, Lagrangian markers, free surface snapshots, wave amplitudes, wave timing, water velocities, water fluxes, and more in an effort to model many aspects of tsunami attack. We will not endeavor to do justice to these many outputs here, in part because we wish to compare our simulation results with known observations and records. Due to the brevity of each case study presented here, further details regarding our simulation results can be found in the literature cited in each section.

\section{The 1946 Unimak, Alaska tsunami}

The 1 April 1946 Alaskan tsunami remains an enigma for several important reasons. First, an apparent underwater landslide scar at least $40 \mathrm{~km}$ long exists in the suspected region of tsunami generation, although the GLORIA data on which this observation is based leaves a lot to be desired when compared to modern sonar techniques. Second, the earthquake source mechanism has undergone many revisions over time that have tended to increase the main shock magnitude from around $M \approx 7$ to $M \approx 8$ (Johnson and Satake, 1997). These revisions may have been made to help explain the devastating transoceanic tsunami that resulted from this event, by first assuming an earthquake source for the tsunami and then by amplifying the seismic energy to explain tsunami observations. Third, Mader and Curtis (1991) needed vertical coseismic displacement of $20 \mathrm{~m}$ to explain the large runup observed in Hawaii. This magnitude of displacement is difficult to reconcile with current marine geology interpretations and typical seismological parameters. Fourth, the earthquake magnitude versus maximum runup produces the largest disparity of any tsunami during the 20th century, larger than even the 1998 Papua New Guinea catastrophe, which suggests a SMF tsunami source. Fifth, despite the large local and transoceanic tsunami damage, there was a very rapid drop in tsunami surface elevation away from a Great Circle axis connecting Unimak Island to the Marquesas Islands and onward to Antarctica. A large earthquake can produce farfield wave energy directivity as if emanating from a very long line source, but only an underwater landslide can produce both near-field and far-field wave energy directivity along its axis of failure (Iwasaki, 1997; Watts, 2001). For large earthquakes, the hypothetical line source perceived in the far-field 
Table 1. Unimak, Alaska tsunami source parameters: The inputs for TOPICS are, in descending order, the specific density $\gamma$, the initial landslide length $b$, the maximum initial landslide thickness $T$, the maximum landslide width $w$, the mean initial landslide depth $d$, and the mean initial incline angle $\theta$. The outputs from TOPICS are the slide initial acceleration $a_{o}$, the theoretical slide terminal velocity $u_{t}$, the characteristic distance of slide motion $s_{o}$, the characteristic time of slide motion $t_{o}$, the characteristic wavelength $\lambda_{o}$, and the characteristic tsunami amplitude $\eta_{o}$ from the depression wave at time $t=t_{o}$

\begin{tabular}{cc}
\hline Quantities & Complete slide \\
\hline$\gamma$ & 1.85 \\
$b(\mathrm{~km})$ & 40 \\
$T(\mathrm{~m})$ & 300 \\
$w(\mathrm{~km})$ & 20 \\
$d(\mathrm{~m})$ & 1700 \\
$\theta($ degrees $)$ & $4.3^{\circ}$ \\
\hline$a_{o}\left(\mathrm{~m} / \mathrm{s}^{2}\right)$ & 0.22 \\
$u_{t}(\mathrm{~m} / \mathrm{s})$ & 199 \\
$s_{O}(\mathrm{~km})$ & 179 \\
$t_{o}(\mathrm{~s})$ & 903 \\
$\lambda_{o}(\mathrm{~km})$ & 117 \\
$\eta_{o}(\mathrm{~m})$ & -64 \\
\hline
\end{tabular}

would usually be oriented parallel to the subducting trench axis; whereas, for a typical underwater landslide, the water waves would be generated along a line parallel to the axis of failure and usually oriented perpendicular to the subducting trench axis. The landslide width will affect tsunami amplitude in the far-field, but not the geometry of tsunami generation described here.

Using the combined model GEOWAVE, we can test the hypothesis that the observed underwater landslide scar can account for the tsunami period of $15 \mathrm{~min}$, which could also be indicative of a massive earthquake in the $7 \mathrm{~km}$ deep waters of the Aleutian Trench. The inputs selected for the SMF tsunami source and basic outputs from TOPICS are given in Table 1. SMF parameters are based on GLORIA sidescan images, properly located ship track data, and ETOPO2 bathymetry. We use Eq. (1e) to take the tsunami period $t_{o} \approx 15 \mathrm{~min}$ and infer a slide length $b \approx 40 \mathrm{~km}$. We find that the predicted slide length agrees with the observed length of the underwater landslide scar. Because the earthquake was in fact relatively weak, probably too weak to explain either near-field or far-field observations, the tsunami appears to have been generated exclusively by a SMF. We speculate that the underwater slide occurred along a weak layer in glacial outwash. The apparent slide thickness $T \approx 300 \mathrm{~m}$ is consistent with typical thickness to length ratios of around $T / b \cong 0.01$ found for most underwater slides (Prior and Coleman, 1979). The underwater slide appears to have had sufficient space along the continental slope to approach terminal velocity, which Eq. (1c) indicates is large on account of the SMF length, a scaling between velocity and length that

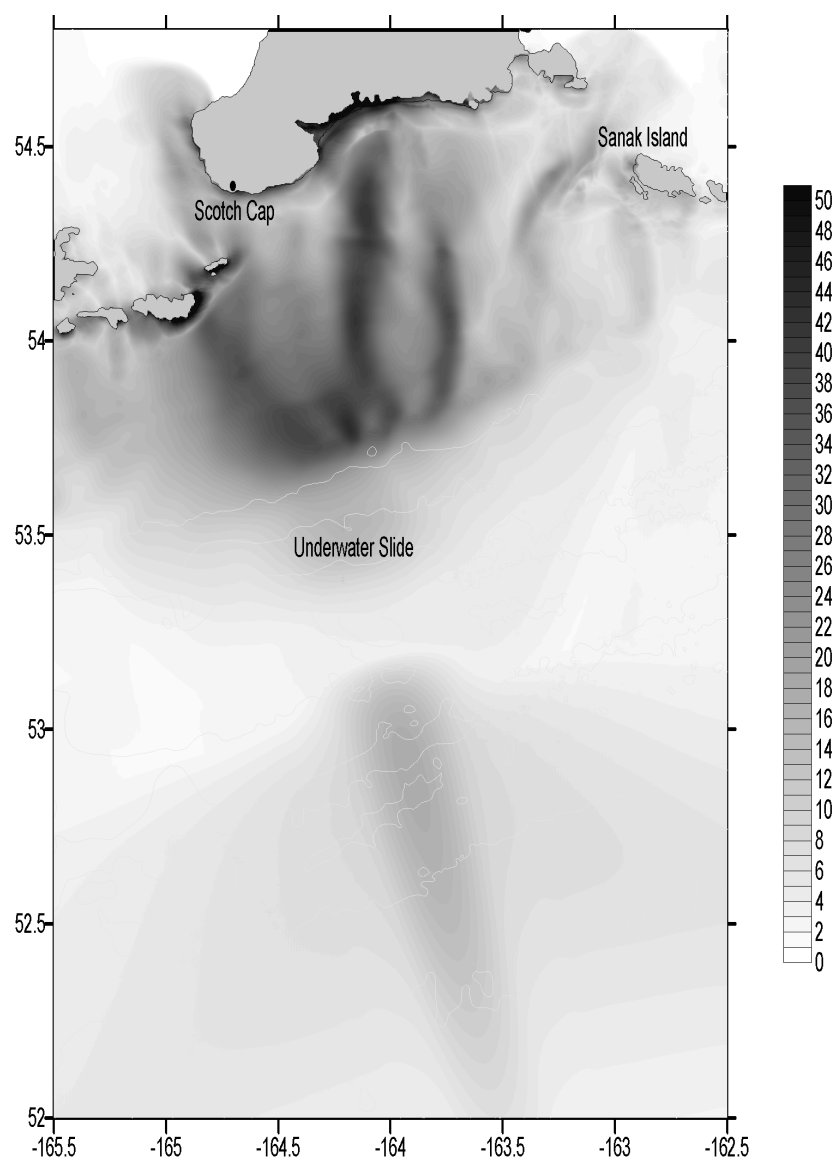

Fig. 3. Maximum tsunami elevation in meters above sea level at any time during a numerical simulation of the 1946 Unimak, Alaska event with an underwater slide tsunami source. North is oriented up. Contours are at $1000 \mathrm{~m}$ intervals. Simulated on a $300 \mathrm{~m}$ grid.

has been verified by Watts and Grilli (2003). The large predicted characteristic tsunami wavelength $\lambda_{o} \approx 117 \mathrm{~km}$ in Table 1 shows that the SMF tsunami would propagate as a shallow water wave almost anywhere within the Pacific Basin. The characteristic tsunami amplitude $\eta_{o} \approx-64 \mathrm{~m}$ is the minimum surface depression of the tsunami source at time $t=t_{o}$ as given by TOPICS.

Figure 3 depicts the GEOWAVE simulation results. The SMF has a headwall located near longitude $-164.2^{\circ}$ and latitude $53.7^{\circ}$, at the current shelf break. The characteristic tsunami wavelength on the shelf, with typical depth $h \approx 100 \mathrm{~m}$, is $\lambda_{o} \sqrt{h / d} \approx 28 \mathrm{~km}$, which gives rise to an Ursell parameter $U \approx 25000$ that indicates highly nonlinear, shallow water waves. We therefore know that Scotch Cap lighthouse was attacked by a very steep wave traversing the continental shelf, quite possibly in the form of a bore. This is supported by the fact that a wave in excess of $40 \mathrm{~m}$ in surface elevation is propagating in water of depth less than $100 \mathrm{~m}$ in depth over considerable distances, greater than $70 \mathrm{~km}$. The wave breaking model in FUNWAVE is therefore a necessary feature of our simulation, a fact that is confirmed by the dark colored fingers in Fig. 3, left behind by breaking waves prop- 


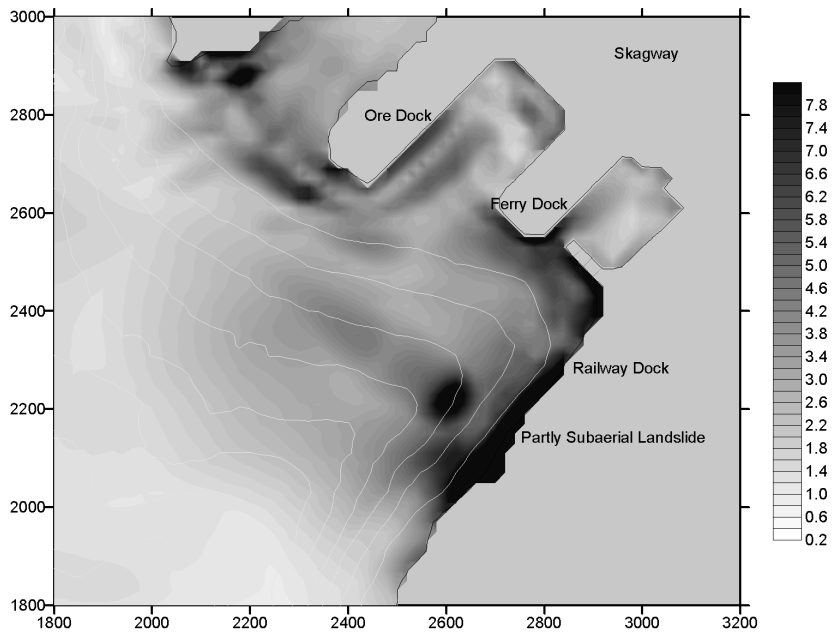

Fig. 4. Maximum tsunami elevation in meters above sea level at any time during a numerical simulation of the 1994 Skagway, Alaska event with Slide $\mathrm{C}$ in Table 2 as the tsunami source. North is oriented up. The grid is in meters with an arbitrary grid origin. Contours are at $20 \mathrm{~m}$ intervals. Simulated on a $10 \mathrm{~m}$ grid.

agating towards Unimak Bight, along the southern edge of Unimak Island. We simulate runup of $36 \mathrm{~m}$ at Scotch Cap lighthouse, which is almost precisely the recorded maximum runup at that location (Lander, 1996). Likewise, the maximum surface elevations off Sanak Island are consistent with local observations. The maximum runup elevation is $108 \mathrm{~m}$ above sea level along Unimak Bight. More important, a beam of tsunami energy with maximum elevation of about $20 \mathrm{~m}$ is projected south towards Hawaii and the Marquesas Islands (Fig. 3). This far-field beam could be predicted on the basis of the landslide velocity in Table 1, which almost matches the long wave celerity above the $7300 \mathrm{~m}$ deep Aleutian trench. These results confirm that large underwater landslides can generate deadly transoceanic tsunamis. While the comparison of our results with all known observations and records is still under way (see Fryer et al., 2003), every comparison made so far has been successful.

\section{The 1994 Skagway, Alaska tsunami}

On 3 November 1994, a partially subaerial landslide in Skagway, Alaska, caused a tsunami that destroyed the southern $300 \mathrm{~m}$ of the railway dock and claimed the life of one construction worker (Kulikov et al., 1996; Campbell and Nottingham, 1999). No seismic activity was recorded but, about 30 min following low tide, loose alluvial sediment slid down the fjord at various locations within Taya Inlet, a fjord terminus within the Alaskan Panhandle (Campbell, 1995; Cornforth and Lowell, 1996). Various estimates of maximum surface elevations caused by the tsunami include $9 \mathrm{~m}$ at the railway dock, $3 \mathrm{~m}$ at the ore dock, and $11 \mathrm{~m}$ at the ferry dock (Watts and Petroff, 1995; Lander, 1996). Figure 4 indicates the locations of these docks within Skagway Harbor. The
Table 2. Skagway, Alaska tsunami source parameters: The inputs for TOPICS are, in descending order, the specific density $\gamma$, the initial landslide length $b$, the maximum initial landslide thickness $T$, the maximum landslide width $w$, the mean initial landslide depth $d$, and the mean initial incline angle $\theta$. The outputs from TOPICS are the slide initial acceleration $a_{o}$, the theoretical slide terminal velocity $u_{t}$, the characteristic distance of slide motion $s_{O}$, the characteristic time of slide motion $t_{o}$, the characteristic wavelength $\lambda_{o}$, and the characteristic tsunami amplitude $\eta_{o}$ from the depression wave at time $t=t_{O}$

\begin{tabular}{cccc}
\hline Quantities & Slide A & Slide B & Slide C \\
\hline$\gamma$ & 1.85 & 1.85 & 1.85 \\
$b(\mathrm{~m})$ & 600 & 215 & 180 \\
$T(\mathrm{~m})$ & 15 & 15 & 20 \\
$w(\mathrm{~m})$ & 340 & 390 & 330 \\
$d(\mathrm{~m})$ & 150 & 95 & 26 \\
$\theta($ degrees $)$ & $9^{\circ}$ & $22^{\circ}$ & $26^{\circ}$ \\
\hline$a_{o}\left(\mathrm{~m} / \mathrm{s}^{2}\right)$ & 0.46 & 1.10 & 1.29 \\
$u_{t}(\mathrm{~m} / \mathrm{s})$ & 35 & 33 & 32 \\
$s_{o}(\mathrm{~m})$ & 2690 & 964 & 807 \\
$t_{o}(\mathrm{~s})$ & 77 & 30 & 25 \\
$\lambda_{o}(\mathrm{~m})$ & 2936 & 904 & 400 \\
$\eta_{o}(\mathrm{~m})$ & -0.54 & -2.06 & -17.3 \\
\hline
\end{tabular}

tsunami source is visible as the dark region offshore at the approximate location $(2600,2200)$. The longshore middle of the partly subaerial landslide is indicated by the text on Fig. 4.

Factors that may have contributed to failure include an exceptionally low tide, recent rip-rap overburden, pile removal operations, artesian water flow through the adjacent mountain, and recent sedimentation from the Skagway river. The Skagway river delta is comprised of fjord walls covered with glacial outwash either from direct emplacement or from sedimentation. This silty sediment is often sensitive to shear waves and can experience an almost total loss of shear strength when disturbed (Bardet, 1997). Therefore, we can expect nearly frictionless underwater slides that are able to trigger further mass failure by undercutting slopes or by retrogressive failure (Bjerrum, 1971).

To simplify this problem, we study three underwater slides in isolation that we think may have been associated with this event: Slide A along the front of the Skagway river delta, Slide B southwest of the railway dock, and Slide C at the railway dock (see Table 2 and Fig. 4). We believe that either Slide A or Slide B failed first, although the order does not particularly matter because either one could have triggered the other. The important observation is that retrogressive failure from one or the other slide led up the fjord floor to Slide C (Campbell, 1995; Plafker et al., 2000). The last line on Table 2 indicates that the majority of wave generation may have occurred around the partly subaerial Slide C, in agreement with the simulation results of Thomson et al. (2001). The analyses in Table 2 are understood to provide a relative 
Table 3. Papua New Guinea tsunami source parameters: The inputs for TOPICS are, in descending order, the longitude of the earthquake centroid $x_{o}$, the latitude of the earthquake centroid $y_{o}$, the centroid depth $d$, the fault strike $\phi$, the fault rake $\lambda$, the fault dip $\delta$, the maximum slip $\Delta$, the fault length along rupture $L$, the fault width across rupture $W$, and the shear modulous $\mu$. The outputs from TOPICS are the seismic moment $M_{o}$, the characteristic wavelength $\lambda_{o}$, and the characteristic tsunami amplitude $\eta_{o}$

\begin{tabular}{cc}
\hline Quantities & Thrust \\
\hline$x_{o}$ (longitude) & $142.16^{\circ}$ \\
$y_{o}$ (latitude) & $-2.88^{\circ}$ \\
$d(\mathrm{~km})$ & 10 \\
$\phi($ degrees $)$ & $112^{\circ}$ \\
$\lambda$ (degrees) & $261^{\circ}$ \\
$\delta($ degrees $)$ & $4^{\circ}$ \\
$\Delta(\mathrm{m})$ & 1.2 \\
$L(\mathrm{~km})$ & 40 \\
$W(\mathrm{~km})$ & 20 \\
$\mu(\mathrm{Pa})$ & $4 \times 10^{10}$ \\
\hline$M_{o}(\mathrm{~J})$ & $3.5 \times 10^{19}$ \\
$\lambda_{o}(\mathrm{~km})$ & 40 \\
$\eta_{o}(\mathrm{~m})$ & -0.3 \\
\hline
\end{tabular}

comparison between tsunami generation by the three slides considered solely in isolation. We note here that these results are obtained without having to run a tsunami propagation and inundation model, which is a potentially useful feature of TOPICS. Our results indicate that all of these potential slides generate dispersive water waves within the fjord, given a maximum depth of Taya Inlet of around $h \approx 220 \mathrm{~m}$. Therefore, any numerical simulation of tsunami propagation that lasts long enough for water waves to traverse the fjord and return to Skagway Harbor should be dispersive.

So far, however, numerical simulations of the Skagway tsunami have been made with propagation models based on (non-dispersive) shallow water wave equations (Raichlen et al., 1996; Kulikov et al., 1996; Kowalik, 1997; Mader, 1997; Fine et al., 1998; Thomson et al., 2001). In most cases, simulation results have not been able to accurately reproduce all of the observed maximum surface elevations. Regardless of the dynamical and spatial complexities associated with tsunami generation in Skagway, we find that simulations for the idealized Slide C, using GEOWAVE, reproduce the $9 \mathrm{~m}$ elevation of a barge located next to the railway dock, as well as the $11 \mathrm{~m}$ elevation of the floating ferry terminal dock. In our work, the sequence of events reported in eyewitness accounts (see Campbell and Nottingham, 1999) is reproduced by the wave that reflects off the shoreline of the destroyed railway dock and then propagates northeast along the shoreline as a highly nonlinear edge wave. The edge wave is represented in Fig. 4 by the dark region near the shoreline that runs from the partially subaerial landslide to the ferry dock. This distinguishes our work from that of Thomson et al. (2001), for instance, who attempt to reproduce the observed wave

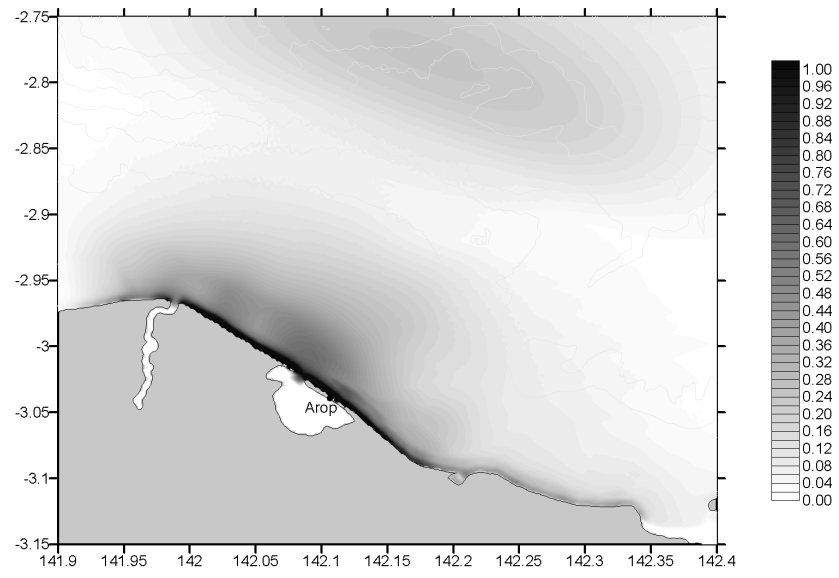

Fig. 5. Maximum elevation in meters above sea level at any time during a numerical simulation of the earthquake source of the 1998 Papua New Guinea event. North is oriented up. Contours are at $500 \mathrm{~m}$ intervals. Simulated on a $100 \mathrm{~m}$ grid.

heights with the elevation wave generated by Slide C, rather than from the reflected wave following the depression wave at the shoreline. The model used by these authors does not generate an appreciable reflected wave, and hence the edge wave is largely absent along the railway dock, contrary to eyewitness accounts. Hence, in our opinion, Thomson et al. (2001) predict wave events earlier than they actually occurred, and underpredict maximum surface elevations by up to $50 \%$ or more near the railway dock, where the edge wave is responsible for maximum surface elevations. For more details regarding the comparison of results or regarding our own case study, we suggest consulting Watts et al. (2003).

\section{The 1998 Papua New Guinea tsunami}

An earthquake of magnitude $M_{W} \cong 7$ struck the northern coast of Papua New Guinea (PNG) in July, 1998 and generated a large tsunami that inundated the coast near Sissano Lagoon, inflicting more than 2000 casualties. The tsunami elevation at the shoreline, over $10 \mathrm{~m}$ above sea level, time of arrival at the shoreline, and longshore distribution of maximum runup are incommensurate with the epicentral location and magnitude of the main shock (Kawata et al., 1999; Tappin et al., 1999). In basic terms, any simulated wave directly generated by the main shock appears to have been too small and too early to relate to eyewitness accounts. The large observed waves can be better explained in terms of a tsunami caused by a sizeable SMF triggered about $12 \mathrm{~min}$ following the earthquake. (Such delays in mass failure are not uncommon, and generally indicate that the causal link between ground motion and failure is complicated.) Here, we test this hypothesis by first simulating the tsunami caused by the shallow dipping subduction zone earthquake and then simulating the tsunami caused by an underwater slump that accounts for both marine geology and water wave observations. 
Table 4. Papua New Guinea tsunami source parameters: The inputs for TOPICS are, in descending order, the specific density $\gamma$, the initial landslide length $b$, the maximum initial landslide thickness $T$, the maximum landslide width $w$, the mean initial landslide depth $d$, and the mean initial incline angle $\theta$. The outputs from TOPICS are the slump initial acceleration $a_{o}$, the maximum slump velocity $u_{\max }$, the characteristic distance of slump motion $s_{O}$, the characteristic time of slump motion $t_{o}$, the characteristic wavelength $\lambda_{o}$, and the characteristic tsunami amplitude $\eta_{o}$ from the depression wave at time $t=t_{O}$

\begin{tabular}{cc}
\hline Quantities & Complete slump \\
\hline$\gamma$ & 2.15 \\
$b(\mathrm{~km})$ & 4.5 \\
$T(\mathrm{~m})$ & 760 \\
$w(\mathrm{~km})$ & 5 \\
$d(\mathrm{~m})$ & 1500 \\
$\theta($ degrees $)$ & $12^{\circ}$ \\
\hline$a_{o}\left(\mathrm{~m} / \mathrm{s}^{2}\right)$ & 0.36 \\
$u_{\max }(\mathrm{m} / \mathrm{s})$ & 11.6 \\
$s_{O}(\mathrm{~km})$ & 375 \\
$t_{O}(\mathrm{~s})$ & 32 \\
$\lambda_{o}(\mathrm{~km})$ & 7.8 \\
$\eta_{o}(\mathrm{~m})$ & -25 \\
\hline
\end{tabular}

The earthquake tsunami initial condition provided by TOPICS (see Table 3 for a summary) matches the offshore bathymetry and onshore topography, meaning that elevated locations such as the offshore "uplifted block" experienced uplift, and a submerged reef as well as Sissano Lagoon experienced subsidence. In other words, coseismic displacement correlated with bathymetry, as one would expect, because vertical relief is presumably a long term expression of similar tectonic processes. In particular, our coseismic displacement reproduces the approximately $15 \mathrm{~cm}$ of subsidence observed around Sissano Lagoon (McSaveny et al., 2000). This suggests that we have interpreted the correct earthquake centroid mechanism and chosen a reasonable earthquake epicenter. Results of the corresponding GEOWAVE simulation are depicted in Fig. 5. Tsunami runup rarely exceeds $1 \mathrm{~m}$ above sea level, and maximum surface elevations occur about $15 \mathrm{~min}$ before the second, larger set of water waves struck, as reconstructed from eyewitness accounts.

Marine surveys, seismic records, and acoustic records indicate that a large SMF occurred, around twelve minutes after the main shock, along the southern edge of an arcuate amphitheater (Tappin et al., 2001). Sediment piston cores, remotely operated vehicle dives, and manned submersible dives confirm the presence of stiff marine clays deposited along a sediment starved margin (Tappin et al., 2002). The tsunami source region has been identified by offshore surveys (Tappin et al., 2001, 2002) and confirmed by numerical simulations (Heinrich et al., 2000). With a thickness to length ratio $T / b \cong 0.17$ and the presence of stiff clays, the SMF was apparently a typical underwater slump that ad-

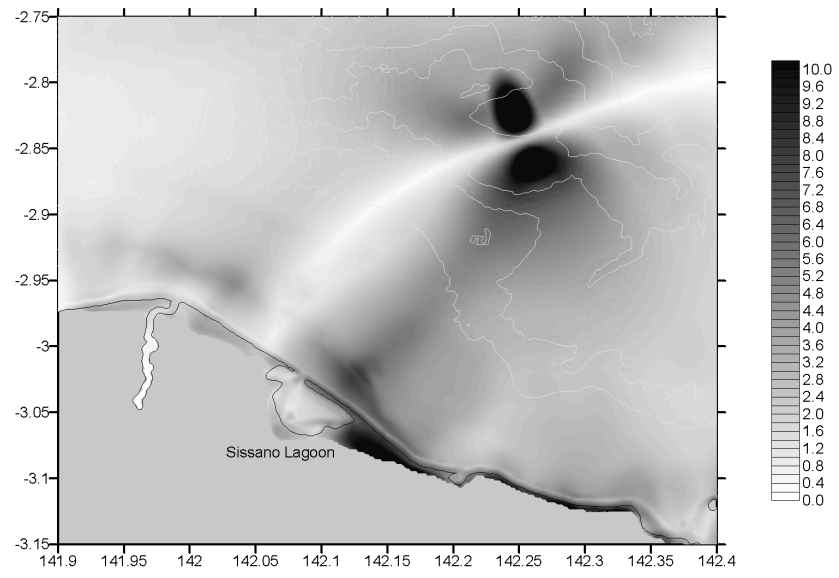

Fig. 6. Maximum elevation in meters above sea level at any time during a numerical simulation of the underwater slump source of the 1998 Papua New Guinea event. North is oriented up. Contours are at $500 \mathrm{~m}$ intervals. Simulated on a $100 \mathrm{~m}$ grid.

vanced only $15 \%$ of its length. The angular displacement was at least two times less than expected for a continental margin covered by stiff clay, which may suggest the involvement of pressurized water in mass failure, in order to mobilize during a transient pulse what should otherwise not have failed (Sibson, 1981; Tappin et al., 2001, 2002). The water pressure would have a tectonic origin and water would have traveled along existing faults, as opposed to pore water pressure, which would be related to sediment strain and would diffuse extremely slowly in stiff clay. Table 4 provides estimated parameters for the underwater slump, provided as inputs for TOPICS, and the corresponding outputs describing the tsunami source. Near the region of tsunami generation, the waves propagate in a manner between deep water waves and shallow water waves (Watts, 2000). The Ursell parameter for this tsunami in an open ocean with depth $h \approx 4 \mathrm{~km}$ is approximately $U \approx 0.0024$, which indicates linear, dispersive wave propagation (Mei, 1983; Watts, 2000). Clearly, the use of a Boussinesq propagation model is in order for simulations of this event. Figure 6 depicts the GEOWAVE simulation results for the underwater slump tsunami source described in Table 4. The SMF is located near longitude $142.25^{\circ}$ and latitude $-2.85^{\circ}$, along the edge of an amphitheater.

A comparison of our simulation results with those of specific nonlinear shallow water wave models is quite instructive. We consider only those simulations based on the marine geology evidence for the underwater slump discussed here. Tappin et al. (2001) used the shallow water wave model TUNAMI-N2 combined with a tsunami source based on 2D BEM simulations. Watts et al. (2002) used the shallow water wave model MOST combined with the same tsunami source. While there are modest differences between the two models, the similarities are far more striking. For both models, the maximum surface elevations occur well offshore, whereas the sand spit fronting Sissano Lagoon barely gets 
covered by water, if at all, in complete contradiction of the onland survey results (Kawata et al., 1999). Synolakis et al. (2002) reinforce our point by repackaging the original work of Watts et al. (2002). We documented significant elevation wave mass loss with TUNAMI-N2, along with some wave reflection, in the region of wave breaking predicted by GEOWAVE. The net result is so pronounced that almost no wave reaches shore. We are not certain as of now if these results are specific to the two shallow water wave models used. Based on this discussion, our current results represent a significant improvement over previous simulations made with an earlier tsunami source and (non-dispersive) shallow water wave tsunami propagation models.

Our GEOWAVE results reproduce the correct times of tsunami arrival relative to two strong aftershocks that occurred roughly $20 \mathrm{~min}$ after the main shock. The two strong aftershocks are the only temporal anchors of the near-field timing of this event. Moreover, we find that the highly nonlinear wave shoaling towards and converging onto Sissano Lagoon broke offshore (see Fig. 6), producing the loud bang and spray on the horizon reported by some people living at Arop village (Watts, 2001). Our results reproduce the observed distribution of maximum runup documented along the affected shoreline (see Kawata et al., 1999) and can also explain the differing accounts as to the number of water waves approaching the shoreline. Those shoreline locations fronted by deep water experienced more than one wave, likely due to increased wave dispersion. Our simulations also demonstrate that survivors from the sand spit would have been swept into the mangrove swamp behind Sissano Lagoon, as actually happened. We find that our use of marine geology information has produced a successful numerical simulation, one that should perhaps be contrasted with similar efforts by other tsunami scientists (e.g. Titov and Gonzalez, 2001; Imamura et al., 2001).

\section{Conclusions}

We proposed a novel modeling strategy and applied software called GEOWAVE to tsunami generation by two types of SMFs: underwater slides, and underwater slumps, each representing approximately 50\% of all SMFs (Schwab et al., 1993). Earlier results showed that reasonable rates of SMF deformation have little effect on major tsunami features. Hence, we only simulate solid (i.e. non-deforming) SMFs. We provide approximate SMF motions as well as tsunami wavelength and amplitude predictions, all of these for both underwater slides and slumps. Tsunami features are in essence transferred from the models of Grilli and Watts (1999) and Grilli et al. (2002) into analytical approximations of tsunami sources by TOPICS. This technique reconstructs an initial condition from SMF tsunami generation to be used with existing tsunami propagation and inundation codes, just like it is customary to treat tsunami generation by coseismic displacement as an initial condition. We conclude that landslide shapes, motions, and tsunami sources are reasonable in our work, because tsunami observations and records are correctly simulated for three independent and very different (in both scale and mechanism) historical case studies, and reproducing observations and records is perhaps the most fundamental measure of successful scientific work. In addition to accurate SMF tsunami sources from TOPICS, we attribute the successful outcome of our case studies to the inclusion of essential geological data and interpretation, as well as the physical capabilities of the Boussinesq propagation model FUNWAVE. Our work demonstrates that the combined software GEOWAVE can produce successful tsunami case studies when provided sufficient geological inputs. We therefore consider to have validated beyond reasonable doubt the techniques and models demonstrated in this work.

Acknowledgements. This paper was funded in part by the US National Science Foundation through grant CMS-0100223 made to STG. Partial funding was also provided by Applied Fluids Engineering, Inc. as well as by the US Geological Survey. DRT publishes with the permission of the British Geological Survey, Natural Environment Research Council, UK. Mention of trade names is for identification purposes only and does not constitute endorsement.

\section{References}

Bardet, J.-P.: Experimental Soil Mechanics, Prentice Hall, Upper Saddle River, New Jersey, 1997.

Bjerrum, L.: Subaqueous slope failures in Norwegian fjords, Nor. Geotech. Inst. Bull., 88, 1-8, 1971.

Campbell, B. A.: Report of a seafloor instability at Skagway, Alaska, 3 November 994, Campbell and Associates, 14104 Hancock Drive, Anchorage, Alaska, 99515, 1995.

Campbell, B. A. and Nottingham, D.: Anatomy of a landslidecreated tsunami at Skagway, Alaska, Sci. Tsunami Hazards, 17, 1, 19-48, 1999.

Chen, Q., Kirby, J. T., Dalrymple, R. A., Kennedy, A. B., and Chawla, A.: Boussinesq modeling of wave transformation, breaking, and runup. II: 2-D, J. Wtrwy, Port, Coast, and Oc. Engrg., ASCE, 126, 1, 48-56, 2000.

Cornforth, D. H. and Lowell, J. A.: The 1994 submarine slope failure at Skagway, Alaska, Landslides, Balkema, 527-532, 1996.

Edgers, L. and Karlsrud, K.: Soil flows generated by submarine slides: Case studies and consequences, Nor. Geotech. Inst. Bull., 143, 1-11, 1982.

Enet, F., Grilli, S. T., and Watts, P.: Laboratory experiments for tsunamis generated by underwater landslides: comparison with numerical modeling, Proc. of the 13th Offshore and Polar Engrg. Conf., ISOPE03, Honolulu, Hawaii, 3, 372-379, 2003.

Fine, I. V., Rabinovich, A. B., Kulikov, E. A., Thomson, R. E., and Bornhold, B. D.: Numerical modelling of landslide-generated tsunamis with application to the Skagway Harbor tsunami of 3 November 1994, Proc., Tsunami Symp., Paris, 1998.

Fryer, G. J., Watts, P., Grilli, S. T., and Kirby, J. T.: Source constraints on the eastern Aleutian tsunami of 1946, J. Geoph. Res., submitted, 2003.

Geist, E. L.: Local tsunamis and earthquake source parameters, Adv. in Geophys., 39, 117-209, 1998.

Goldfinger, C., Kulm, L. D., McNeill, L. C., and Watts, P.: Superscale failure of the Southern Oregon Cascadia Margin, PAGEOPH, 157, 1189-1226, 2000. 
Grilli, S. T. and Watts, P.: Modeling of waves generated by a moving submerged body: Applications to underwater landslides, Engrg. Analysis with Boundary Elements, 23, 8, 645-656, 1999.

Grilli, S. T. and Watts, P.: Modeling of tsunami generation by an underwater landslide in a 3-D numerical wave tank, Proc. of the 11th Offshore and Polar Engrg. Conf., ISOPE01, Stavanger, Norway, 3, 132-139, 2001.

Grilli, S. T., Vogelmann, S., and Watts, P.: Development of a 3-D numerical wave tank for modeling tsunami generation by underwater landslides, Engrg. Analysis with Boundary Elements, 26, 4, 301-313, 2002.

Hammack, J. L.: A note on tsunamis: Their generation and propagation in an ocean of uniform depth, J. Fluid Mech., 60, 769-799, 1973.

Hampton, M. A., Lee, H. J., and Locat, J.: Submarine landslides, Rev. Geophys., 34, 1, 33-59, 1996.

Heinrich, P., Piatanesi, A., Okal, E. A., and Hebert, H.: Near-field modeling of the 17 July 1998 tsunami in Papua New Guinea, Geophys. Res. Lett., 27, 3037-3040, 2000.

Imamura, F., Hashi, K., and Imteaz, M. A.: Modeling for tsunamis generated by landsliding and debris flow, in: Tsunami Research at the End of a Critical Decade, edited by Hebenstreit, G. T., Kluwer Academic Publishers, 209-228, 2001.

Iwasaki, S.: The wave forms and directivity of a tsunami generated by an earthquake and a landslide, Sci. Tsunami Hazards, 15, 2340, 1997.

Johnson, J. M. and Satake, K.: Estimation of seismic moment and slip distribution of the 1 April 1946, Aleutian tsunami earthquake, J. Geoph. Res., 102, 11 765-11 774, 1997.

Kawata, Y. and International Tsunami Survey Team members: Tsunami in Papua New Guinea was intense as first thought, Eos, Trans. Am. Geophys. Union, 80, 9, 101, 1999.

Keating, B. H. and McGuire, W. J.: Island edifice failures and associated tsunami hazards, Pure Appl. Geophys., 157, 899-955, 2000.

Kennedy, A. B., Chen, Q., Kirby, J. T., and Dalrymple, R. A.: Boussinesq modeling of wave transformation, breaking, and runup. I: 1D, J. Wtrwy, Port, Coast, and Oc. Engrg., ASCE, 126, 1, 39-47, 2000.

Kowalik, Z.: Landslide-generated tsunami in Skagway, Alaska, Sci. Tsunami Hazards, 15, 2, 89-106, 1997.

Kulikov, E. A., Rabinovich, A. B., Thomson, R. E., and Bornhold, B. D.: The landslide tsunami of 3 November 1994, Skagway harbor, Alaska, J. Geoph. Res., 101, C3, 6609-6615, 1996.

Lander, J. F.: Tsunamis affecting Alaska 1737-1996. Publication 31, Nat. Geophysical Data Ctr., Nat. Envir. Satellite, Data, and Info. Service, Nat. Oceanic and Atmospheric Admin., U.S., Dept. of Commerce, Boulder, CO, 1996.

Liu, P. L.-F., Yeh, H., Lin, P., Chang, K.-T., and Cho, Y.-S.: Generation and evolution of edge-wave packets, Phys. Fluids, 10, 7, 1635-1657, 1998.

Mader, C. L. and Curtis, G.: Modeling Hilo, Hawaii tsunami inundation, Sci. Tsunami Hazards, 9, 85-94, 1991.

Mader, C.: Modeling the 1994 Skagway tsunami, Sci. Tsunami Hazards, 15, 1, 41-48, 1997.

McSaveny, M. J., Goff, J. R., Darby, D. J., Goldsmith, P., Barnett, A., Elliot, S., and Nongkas, M.: The 17 July, 1998 tsunami, Papua New Guinea: Evidence and initial interpretation, Marine Geology, 170, 81-92, 2000

Mei, C. C.: The applied dynamics of ocean surface waves, World Scientific, Teaneck, N.J., 1983.

Murty, T. S.: Submarine slide-generated water waves in Kitimat
Inlet, British Columbia, J. Geoph. Res., 84, C12, 7777-7779, 1979.

Okada, Y.: Surface deformation due to shear and tensile faults in a half-space, Bull. Seis. Soc. Am., 75, 4, 1135-1154, 1985.

Pelinovsky, E. and Poplavsky, A.: Simplified model of tsunami generation by submarine landslide, Phys. Chem. Earth, 21, 12, 1317, 1996

Plafker, G., Greene, H. G., Maher, N., and Synolakis, C. E.: Mechanism of the 3 November 1994 submarine landslide and associated landslide-generated tsunami at Skagway, Alaska, Eos, Trans. Am. Geophys. Union, 81, 48, f759, 2000.

Prior, D. B. and Coleman, J. M.: Submarine landslides: Geometry and nomenclature, Z. Geomorph. N. F., 23, 4, 415-426, 1979.

Raichlen, F., Lee, J. J., Petroff, C., and Watts, P.: The generation of waves by a landslide: Skagway, Alaska case study, Proc., 25th Int. Conf. Coastal Engrg., Orlando, FA, ASCE, 1293-1300, 1996.

Schwab, W. C., Lee, H. J., and Twichell, D. C.: Submarine landslides: Selected studies in the U.S. exclusive economic zone, Bull. 2002, U.S. Geol. Surv., U.S., Dept. of Interior, Washington, DC, 1993.

Sibson, R. H.: Controls on low stress hydro-fracture dilatancy in thrust wrench and normal fault terranes, Nature, 289, 665-667, 1981.

Striem, H. L. and Miloh, T.: Tsunamis induced by submarine slumpings off the coast of Israel, Int. Hydrographic Review, 2, $41-55,1976$

Synolakis, C. E., Bardet, J. P., Borrero, J. C., Davies, H. L., Okal, E. A., Silver, E. A., Sweet, S., and Tappin, D. R.: The slump origin of the 1998 Papua New Guinea tsunami, Proc. Royal. Soc., London, 458, 763-790, 2002.

Tappin, D. R. and Shipboard Scientists: Offshore surveys identify sediment slump as likely cause of devastating Papua New Guinea tsunami 1998, Eos, 80, 30, 27 July 329, 1999.

Tappin, D. R., Watts, P., McMurtry, G. M., Lafoy, Y., and Matsumoto, T.: The Sissano, Papua New Guinea tsunami of July 1998 - Offshore evidence on the source mechanism, Marine Geology, 175, 1-23, 2001.

Tappin, D. R., Watts, P., McMurtry, G. M., Lafoy, Y., and Matsumoto, T.: Prediction of slump generated tsunamis: The 17 July 1998 Papua New Guinea event, Sci. Tsunami Hazards, 20, 4, 222-238, 2002.

Thomson, R. E., Rabinovich, A. B., Kulikov, E. A., Fine, I. V., and Bornhold, B. D.: On numerical simulation of the landslidegenerated tsunami of 3 Novemebr 1994 in Skagway Harbor, Alaska, in: Tsunami Research at the End of a Critical Decade, edited by Hebenstreit, G. T., Kluwer Academic Publishers, 243 282, 2001.

Tinti, S., Bortolucci, E., and Chiavettieri, C.: Tsunami excitation by submarine slides in shallow-water approximation, PAGEOPH, 158, 759-797, 2001.

Titov, V. V. and Gonzalez, F. I.: Numerical study of the source of the 17 July 1998 PNG tsunami." in: Tsunami Research at the End of a Critical Decade, edited by Hebenstreit, G. T., Kluwer Academic Publishers, 197-207, 2001.

Turner, A. K. and Schuster, R. L.: Landslides: Investigation and mitigation, Special Report 247, Trans. Res. Board, National Academy Press, Washington, DC, 1996.

Ward, S. N.: Landslide tsunami, J. Geoph. Res., 106, 6, $11201-$ 11215, 2001.

Watts, P.: Water waves generated by underwater landslides, $\mathrm{PhD}$ thesis, California Inst. of Technol., Pasadena, CA., 1997. 
Watts, P.: Wavemaker curves for tsunamis generated by underwater landslides, J. Wtrwy, Port, Coast, and Oc. Engrg., ASCE, 124, 3, 127-137, 1998.

Watts, P.: Tsunami features of solid block underwater landslides, J. Wtrwy, Port, Coast, and Oc. Engrg., ASCE, 126, 3, 144-152, 2000.

Watts, P., Imamura, F., and Grilli, S. T.: Comparing model simulations of three benchmark tsunami generation cases, Sci. Tsunami Hazards, 18, 2, 107-124, 2000.

Watts, P.: Some opportunities of the landslide tsunami hypothesis, Sci. Tsunami Hazards, 19, 3, 126-149, 2001.

Watts, P.: Probabilistic predictions of landslide tsunamis off Southern California, Marine Geology, accepted, 2003.

Watts, P., Borrero, J. C., Tappin, D. R., Bardet, J.-P., Grilli, S. T., and Synolakis, C. E.: Novel simulation technique employed on the 1998 Papua New Guinea tsunami, presented at the 1999
IUGG General Assembly in Birmingham, UK, and published by the first author at www.appliedfluids.com/resume.html, 2002.

Watts, P. and Grilli, S. T.: Underwater landslide shape, motion, deformation, and tsunami generation, Proc. of the 13th Offshore and Polar Engrg. Conf., ISOPE03, Honolulu, Hawaii, 3, 364371, 2003.

Watts, P., Grilli, S. T., and Kirby, J. T.: Tsunami hazards at Skagway, Alaska, J. Geoph. Res., submitted, 2003.

Watts, P. and Petroff, C. M.: Summary of preliminary findings on the Skagway tsunami, Tsunami Bulletin Board, January, 1995.

Wei, G. and Kirby, J. T.: Time-dependent numerical code for extended Boussinesq equations, J. Wtrwy, Port, Coast, and Oc. Engrg., ASCE, 121, 5, 251-261, 1995.

Wei, G., Kirby, J. T., Grilli, S. T., and Subramanya, R.: A fully nonlinear Boussinesq model for free surface waves. Part 1: Highly nonlinear unsteady waves, J. Fluid Mech., 294, 71-92, 1995. 